\title{
POC-Scale Testing of an Advanced Fine Coal Dewatering Equipment/Technique
}

\author{
Quarterly Report \\ January 1 - March 31, 1998
}

\author{
By \\ D. Tao; J. G. Groppo \\ B. K. Parekh
}

Work Performed Under Contract No.: DE-AC22-94PC94155

\author{
For \\ U.S. Department of Energy \\ Office of Fossil Energy \\ Federal Energy Technology Center \\ P.O. Box 880 \\ Morgantown, West Virginia 26507-0880 \\ By \\ Center for Applied Energy Research \\ University of Kentucky \\ Lexington, Kentucky 40511
}




\section{Disclaimer}

This report was prepared as an account of work sponsored by an agency of the United States Government. Neither the United States Government nor any agency thereof, nor any of their employees, makes any warranty, express or implied, or assumes any legal liability or responsibility for the accuracy, completeness, or usefulness of any information, apparatus, product, or process disclosed, or represents that its use would not infringe privately owned rights. Reference herein to any specific commercial product, process, or service by trade

name, trademark, manufacturer, or otherwise does not necessarily constitute or imply its endorsement, recommendation, or favoring by the United States Government or any agency thereof. The views and opinions of authors expressed herein do not necessarily state or reflect those of the United States Government or any agency thereof. 


\title{
QUARTERLY TECHNICAL PROGRESS
}

REPORT 14

January - March 1998

POC-SCALE TESTING

OF AN ADVANCED FINE COAL DEWATERING EQUIPMENT/TECHNIQUE

\author{
Prepared for \\ U.S. Department of Energy \\ Pittsburgh Energy Technology Center \\ Pittsburgh, PA 15236 \\ By \\ D. Tao \\ J.G. Groppo \\ B.K. Parekh \\ Center for Applied Energy Research \\ University of Kentucky \\ Lexington, KY 40511
}

DOE Contract No. DE-AC22-94PC94155

August 28, 1998 


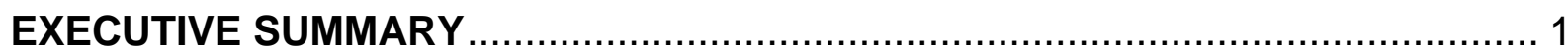

OBJECTIVES AND SCOPE OF THE PROJECT ....................................... 1

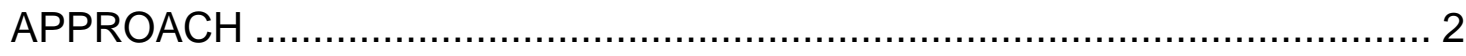

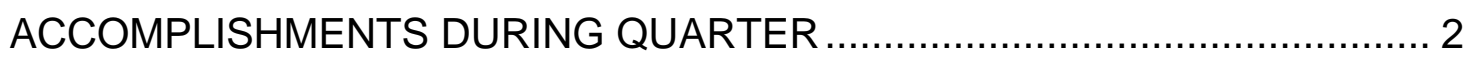

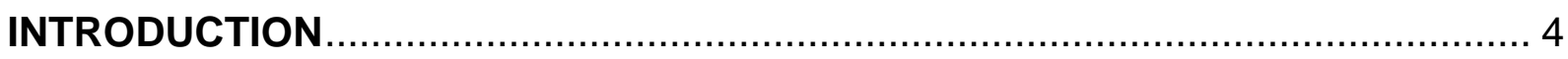

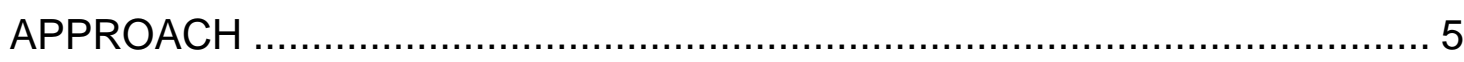

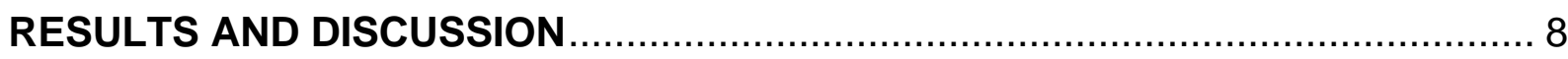

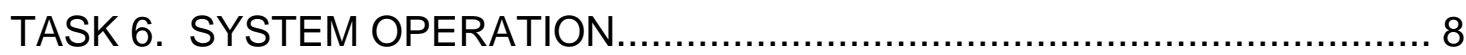

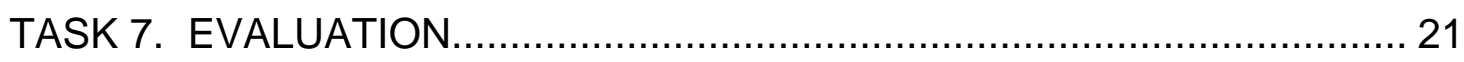

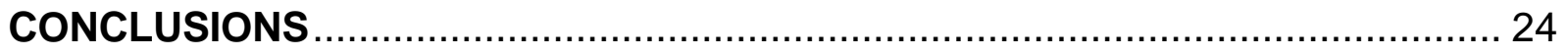

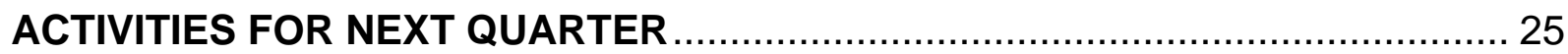




\section{LIST OF FIGURES}

Figure 1. Project management organization chart......................................6

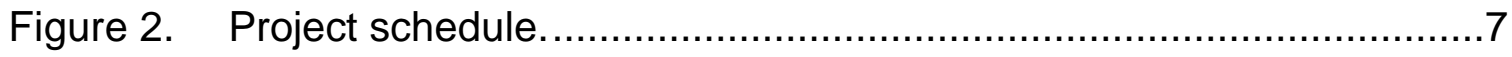

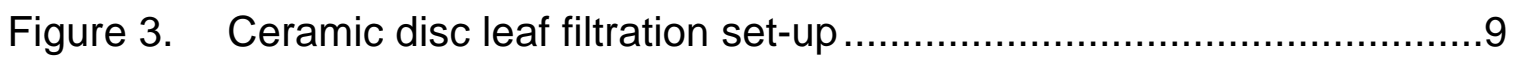

Figure 4. Dewatering/drying stage of the filter cake ....................................

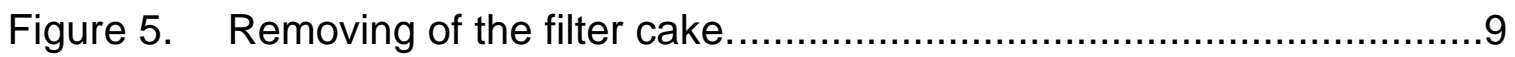

Figure 6. Effects of cake formation time on solids loading and cake moisture using the as-received coal slurry....................................13

Figure 7. Effects of cake formation time on solids loading and cake moisture using the pre-thickened coal slurry.................................14

Figure 8. Effects of cake drying time on solids loading and cake moisture using the pre-thickened coal slurry................................16

Figure 9. Effects of cake formation time on solids loading and cake moisture using the pre-thickened coal slurry....

Figure 10. Effects of cake drying time on solids loading and cake moisture using the pre-thickened coal slurry

Figure 11. Effects of anionic flocculant on solids loading and cake moisture using the as-received coal slurry

Figure 12. Effects of anionic flocculant on solids loading and cake moisture using the pre-thickened coal slurry....

Figure 13. Effects of cationic flocculant on solids loading and cake moisture using the pre-thickened coal slurry 


\section{EXECUTIVE SUMMARY}

Froth flotation technique is an effective and efficient process for recovering of ultra-fine (minus $74 \mu \mathrm{m}$ ) clean coal. Economical dewatering of an ultra-fine clean coal product to a $20 \%$ level moisture will be an important step in successful implementation of the advanced cleaning processes. This project is a step in the Department of Energy's program to show that ultra-clean coal could be effectively dewatered to $20 \%$ or lower moisture using either conventional or advanced dewatering techniques.

The cost-sharing contract effort is for 45 months beginning September 30 , 1994. This report discusses technical progress made during the quarter from January 1 - March 31, 1998.

\section{OBJECTIVES AND SCOPE OF THE PROJECT}

The main objective of the proposed program is to evaluate a novel surface modification technique, which utilizes the synergistic effect of metal ionssurfactant combination, for dewatering of ultra-fine clean coal on a proof-ofconcept scale of 1 to 2 tph. The novel surface modification technique developed at the UKCAER along with the use of conventional reagents was evaluated using vacuum, centrifuge, and hyperbaric filtration equipment. Dewatering tests were conducted using the fine clean coal froth produced by the column flotation units at the Powell Mountain Coal Company, Mayflower Preparation Plant in St. Charles, Virginia. The POC-scale studies were conducted on two different types of clean coal, namely, high-sulfur and low-sulfur clean coal produced at the 
plant. The Mayflower Plant processes coals from five different seams, thus the dewatering results could be generalized for most of the bituminous coals.

\section{APPROACH}

The project team consisted of the University of Kentucky Center for Applied Energy Research (UKCAER), Powell Mountain Coal Company (PMCC), Andritz Ruthner Inc., WesTech Engineering Inc., and Decanter Machine, Inc.

The UKCAER is the prime contractor of the project which has been divided into nine (9) tasks. The clean coal froth generated by the 'Ken-Flote' columns at the PMCC Mayflower Preparation Plant was utilized for dewatering studies using hyperbaric, centrifuge and vacuum dewatering techniques.

Based on the DOE project monitor's suggestions additional dewatering studies were also initiated using the Otokumpu's ceramic disc filter.

\section{ACCOMPLISHMENTS DURING THE QUARTER}

Laboratory ceramic filter dewatering tests with the PMCC low-sulfur coal slurry have shown that cake drying time affected cake moisture, whereas cake formation time increased both solids loading and cake moisture. The effect of cake formation time on solids loading was more significant with the low-solids content (12.8\%) slurry than the thickened high-solids content (25\%) slurry.

The low-porosity ceramic filter produced slightly lower solids loading but significantly lower cake moisture than high-porosity filter. For example, at a 45 second cake formation time and 30 second cake drying time, the low-porosity filter produced a cake moisture of $27.5 \%$ at a solids loading $1.00 \mathrm{~kg} / \mathrm{m}^{2}$, while the 
high-porosity filter generated a cake moisture of $31.2 \%$ at a solids loading of $1.15 \mathrm{~kg} / \mathrm{m}^{2}$. The difference in solids loading between the low-porosity and highporosity filters decreased with increasing the cake formation time.

Addition of $5 \mathrm{~g} / \mathrm{t}$ of anionic flocculant to the 'as received' PMCC slurry reduced cake moisture from $22.7 \%$ to $15.9 \%$ using the high-porosity filter. Increasing solids concentration to $25 \%$ increased filter cake moisture from $32.5 \%$ to 36.3 . Addition of cationic flocculant was not effective in lowering the filter cake moisture, however, it increased solid loading from $1.5 \mathrm{~kg} / \mathrm{m}^{2}$ to 2.62 $\mathrm{kg} / \mathrm{m}^{2}$ using $25 \mathrm{~g} / \mathrm{t}$ of the flocculant. Addition of $0.4 \mathrm{~kg} / \mathrm{t}$ of the cationic surfactant CPCL lowered filter cake moisture from $28.1 \%$ to $22.4 \%$ using the low-porosity filter. However, with high-porosity filter the cake moisture increased from $25.5 \%$ to $29.1 \%$ at a surfactant dosage of $0.8 \mathrm{~kg} / \mathrm{t}$.

It was observed that the baseline dewatering data were ranging significantly, which was attributed to the constantly changing house vacuum. Next quarter all the tests will be conducted using a portable vacuum pump. 


\section{INTRODUCTION}

For cleaning of coal finer than $0.5 \mathrm{~mm}$ (28 mesh) processes based on surface chemical technique such as froth flotation and oil agglomeration are the most effective. However, the froth flotation process, which is commercially used, produces a product containing about $80 \%$ moisture. The recently developed column flotation technique provides for the higher recovery of low-ash product, but also suffers from the same problem of high moisture product. Dewatering of the fine coal to a low ( 20\%) moisture level using the conventional filtration equipment has not been possible. This project offers a novel surfacemodification approach to modify coal surface so it could dewater to a low moisture level using conventional and advanced dewatering equipment.

The aim of this program is to test the UKCAER-developed novel coal surface modification approach on a pilot scale at the rate of 1-2 tph of solids using vacuum, centrifuge and hyperbaric filtration technique. This proof-ofconcept testing was performed at the Powell Mountain Coal Company Mayflower Plant located in St. Charles, Virginia.

The project involved a teaming arrangement between the University of Kentucky for Applied Energy Research (CAER), the Powell Mountain Coal Company (PMCC), the Andritz Ruthner Inc. (ARI), WesTech Engineering Inc., and Decanter Machine, Inc. 


\section{APPROACH}

A team of scientists and engineers from the Center for Applied Energy Research, Powell Mountain Coal Company, and equipment manufacturers was formed to accomplish the objectives of the program. Each team member brought fine particle dewatering knowledge and experience to the project. The UKCAER, who is the prime contractor, manages the project and conducts the major part of the study. The PMCC provided assistance and facility in conducting the pilot scale tests, and ARI conducted laboratory dewatering tests and also pilot scale tests using the hyperbaric pressure filtration unit at the PMCC. Figure 1 shows the project organization chart. The project schedule for the program is shown in Figure 2.

The CAER collected clean coal froth samples from the Mayflower plant for the laboratory studies. Samples of clean coal slurries were also sent to ARI for studies using their laboratory-scale hyperbaric unit. At both organizations, it was emphasized to identify optimum process and operating conditions using vacuum and pressure techniques to dewater the clean coal slurry to about the $20 \%$ level moisture. It is believed that the proposed research can produce low moisture products on a pilot scale to the same extent which has already been achieved in laboratory studies.

The basic components of the process has been tested in laboratory. The purpose of the proposed work here is to evaluate all of the component steps on a consistent basis, and, to the extent possible in laboratory studies, demonstrate 


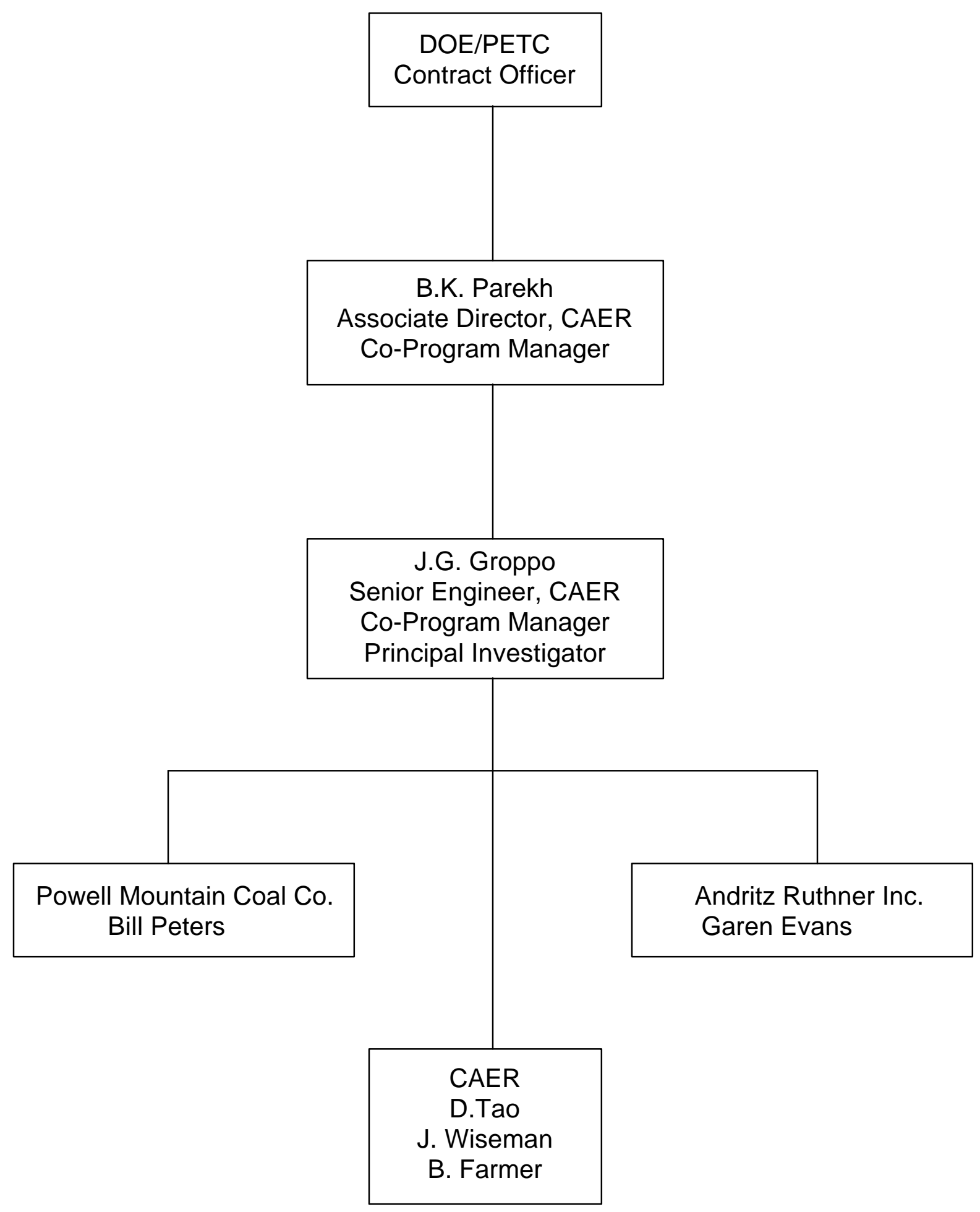

Figure 1. Project management organization chart 


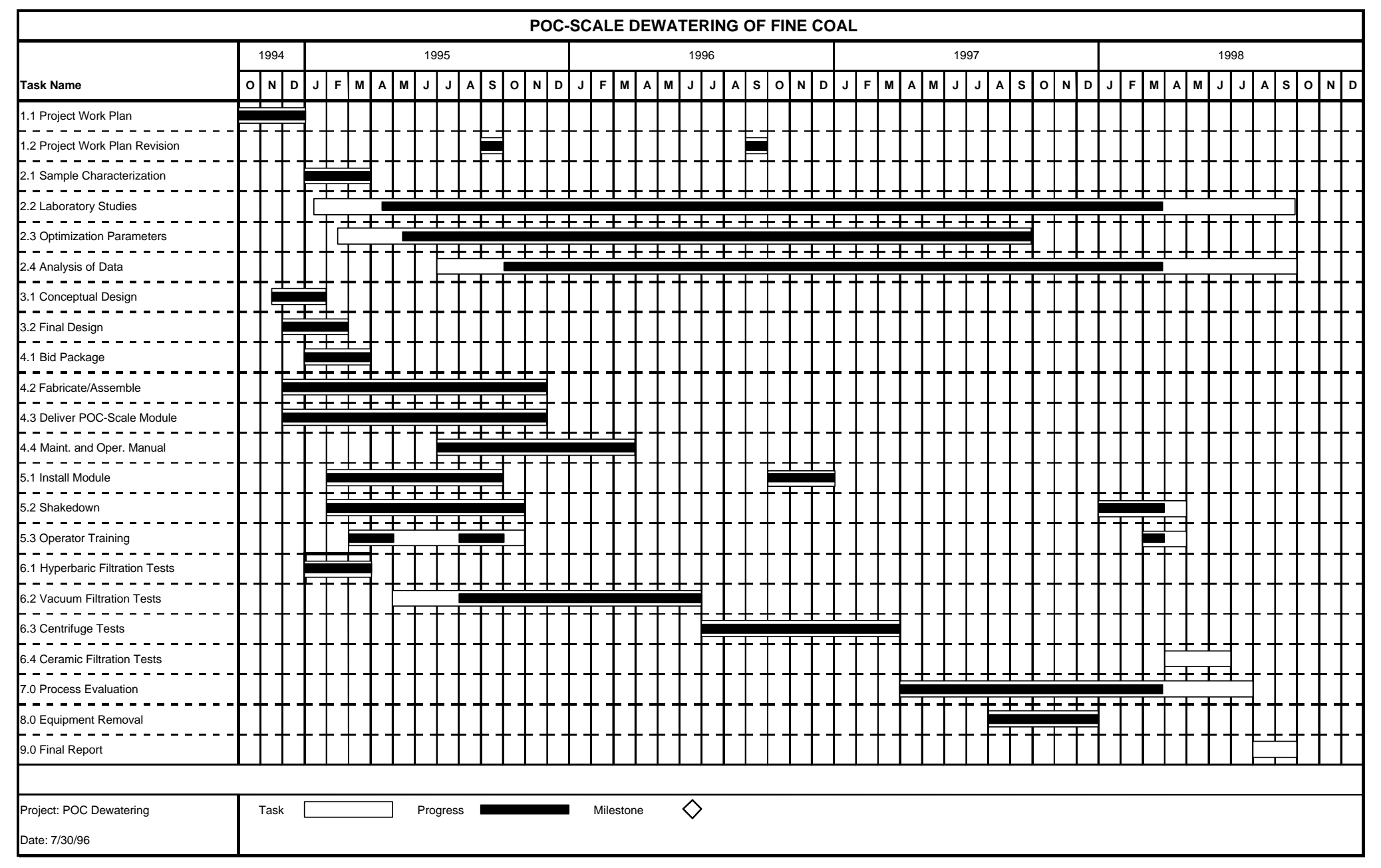

Figure 2. Up-to-date project schedule 
the feasibility of their integration. The outcome of this program will be to identify a process/technique combination which is able to achieve a $20 \%$ or lower moisture in the fine clean coal product and to provide a technical and economic evaluation of the integrated concept in sufficient detail for a coal company to assess the potential for installation of the dewatering process in their plant.

\section{RESULTS AND DISCUSSION}

The project has been divided into tasks and subtasks listed in Table 1. Each task and subtask has a specific objective which can be inferred from its title. During this quarter (January 1 to March 30,1998) work was done on Tasks 6 and 7.

\section{Task 6. System Operation}

\section{Ceramic Filter Dewatering}

During the past quarter laboratory filter leaf dewatering tests were conducted with PMCC compliance (low- sulfur) coal slurry using the Outokumpu ceramic leaf filter apparatus. Figures 3,4 , and 5 show the experimental steps utilized for the ceramic filter tests. For all the tests the coal slurry was kept stirred during cake formation stage to provide uniform distribution and deposition of coal particles on the filter. Two different types of ceramic leaf filters were tested - one with high-porosity (water flow rate 3 liter/minute at 1 bar or 14.6 psig) and one with low-porosity (water flow rate 0.6 liter/minute at 1 bar or 14.6 psig). The objective of this work is to identify optimum process conditions to 


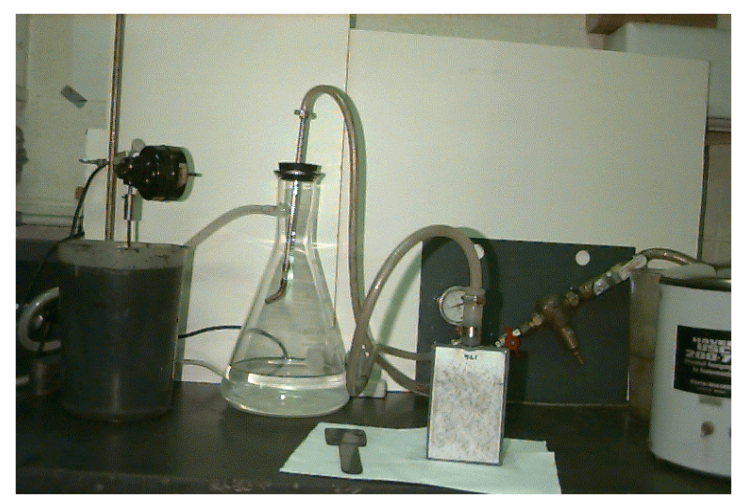

Figure 3. Ceramic disc leaf filtration set-up

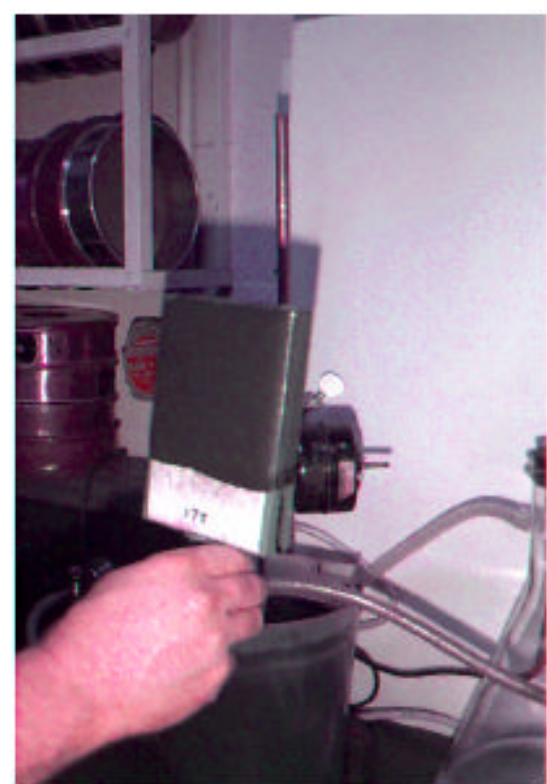

Figure 4. Dewatering/drying stage of the filter cake

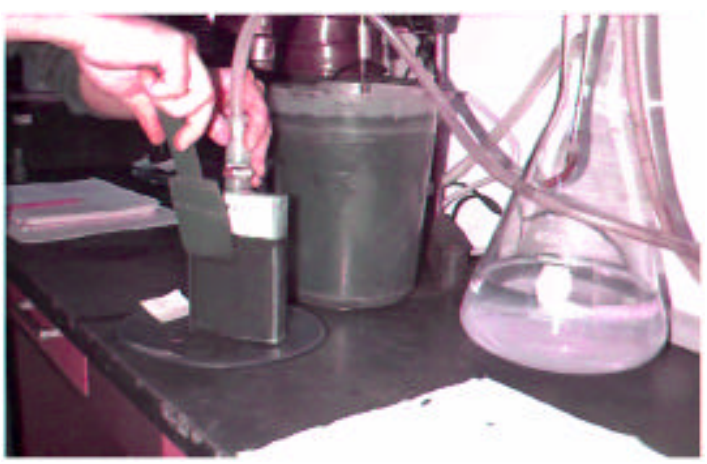

Figure 5. Removing of the filter cake 
Table I. Outline of Work Breakdown Structure

Task 1. Project Work Planning

Subtask $1.1 \quad$ Project Work Plan

Subtask 1.2 Project Work Plan Revisions

Task 2. Samples Analysis and Laboratory Testing

Subtask 2.1 Acquisition and Characterization of Samples

Subtask 2.2 Laboratory Scale Testing

Subtask 2.3 Optimization of Parameters

Subtask 2.4 Analysis of Data

Task 3. Engineering Design

Subtask 3.1 Conceptual Design Package

Subtask 3.2 Final Design Package

Subtask 3.3 Construction Schedule

Task 4. Procurement and Fabrication

Subtask 4.1 Bid Packages

Subtask 4.2 Fabricate/Assemble Components

Subtask 4.3 Deliver POC-Scale Module and Install

Subtask 4.4 Maintenance and Operating Manual

Task 5. Installation and Shakedown

Subtask 5.1 Install and Tie-in Module

Subtask 5.2 Startup Procedures/Shakedown

Subtask $5.3 \quad$ Operators Training

Task 6. System Operation

Subtask 6.1 Test Coal No. 1

Subtask 6.2 Test Coal No. 2

Task 7. Process Evaluation

Task 8. Equipment Removal

Task 9. Reporting

Subtask 9.1 Monthly Reports

Subtask 9.2 Project Final Report 
enhance the dewatering of fine coal slurry using the ceramic disc filter and to provide guidelines for the pilot-scale testing. This objective is being accomplished by investigating the effects of the addition of various reagents to coal slurry on ceramic disc dewatering performance under different operating conditions. The reagents used in this work are believed to enhance coal dewatering by modifying the coal surface to provide favorable dewatering characteristics such as:

- high hydrophobicity

- low surface tension

- large aggregate size

- high permeability of filter cake, etc.

Reagents to be tested using the ceramic filter include anionic (sodium 2-ethylhexyl sulfate), nonionic (octyl phenoxy polyethoxy ethanol), and cationic 1-hexadecyl pyridinium chloride (commercial name cetyl pyridinium chloride (CPCL)) surfactants; anionic Procol 156 and cationic Procol 371 flocculants; trivalent and divalent metal ions $\left(\mathrm{Al}^{3+}\right.$ and $\left.\mathrm{Cu}^{2+}\right)$. In the last quarter, major efforts were devoted to the investigation of effects of addition of anionic Procol 156 and cationic Procol 371 flocculants, as well as, cationic cetyl pyridinium chloride (CPCL) surfactant on the dewatering of fine coal slurry using the ceramic filter. Both the high-porosity and low-porosity ceramic filters were used in the dewatering tests. All the experiments were performed using the house vacuum. 
Figure 6 shows the baseline test results obtained using the high-porosity ceramic filter and a constant cake drying time (CDT) of 30 seconds. The tests were conducted with the as-received clean-coal froth slurry from the PMCC containing $12.8 \%$ solids. As cake formation time increased from 15 to 60 seconds, cake moisture increased from 23.7 to $27.7 \%$. The increase in cake moisture is clearly a result of increased solids loading which varied from 0.38 to $0.95 \mathrm{~kg} / \mathrm{m}^{2}$. Increase in solids loading (or cake thickness) increased cake resistance and hence higher cake moisture.

The Outokumpu Co. personnel pointed out that the ceramic disc filter operates much more efficiently and effectively with high percent solids slurry. Figure 7 shows the baseline dewatering test data obtained using the coal slurry thickened to 25 weight percent solids. As cake formation time increased from 15 seconds to 60 seconds, solids loading increased from 0.72 to $1.1 \mathrm{~kg} / \mathrm{m}^{2}$, which is significantly higher than that obtained with the as-received coal slurry, particularly at shorter cake formation time. However, cake moisture obtained with the thickened slurry also increased considerably at longer cake formation time. For example, filter cakes with $31.2 \%$ and $36.1 \%$ moisture were obtained using cake formation time of 45 and 60 seconds, respectively, compared to $26.5 \%$ and $27.7 \%$ moisture obtained with the as-received coal slurry in Figure 6. The results indicate that a shorter cake formation time is favorable for the ceramic disc filter using high solids slurry. 


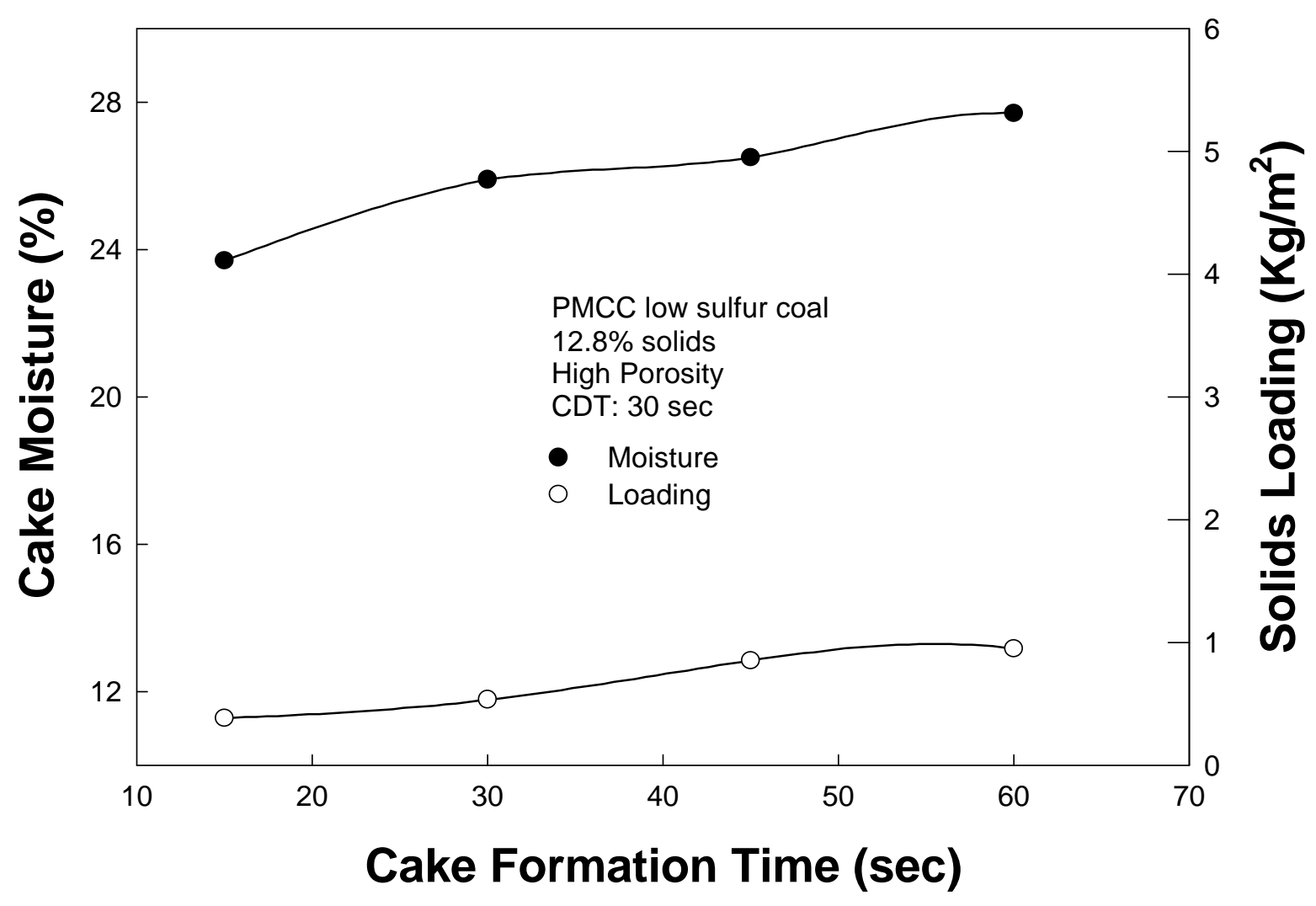

Figure 6. Effect of cake formation time on solids loading and cake moisture with as received coal slurry using the high porosity ceramic filter 


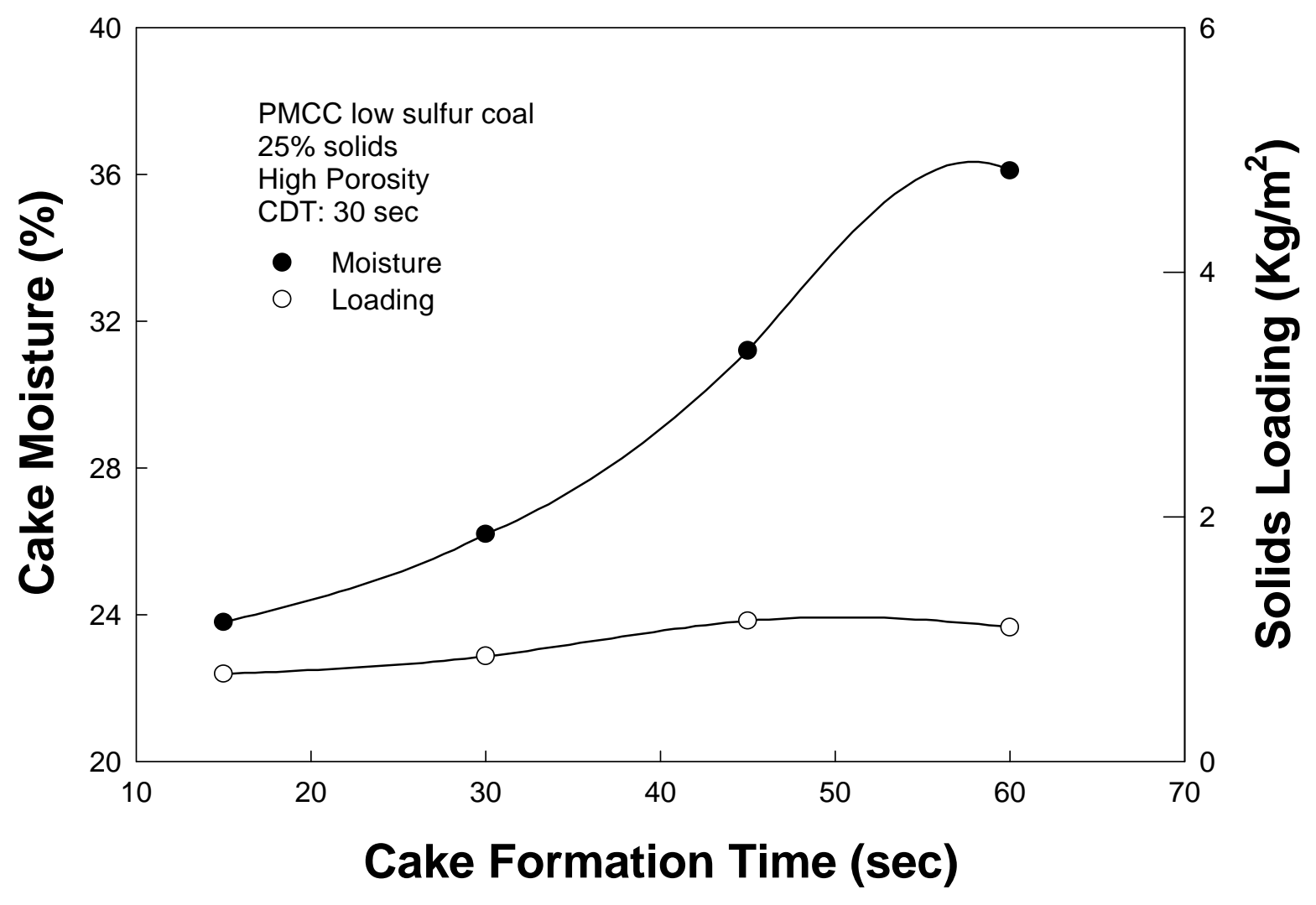

Figure 7. Effects of cake formation time on solids loading and cake moisture with pre-thickened coal slurry using the high porosity filter 
Figure 8 shows ceramic filter dewatering test results obtained using the low-porosity ceramic filter and the constant cake drying time (CDT) of 30 seconds. The coal slurry used for the test was also pre-thickened to 25 weight percent solids. The filter cake moisture increased from $22.6 \%$ to $32.7 \%$ as the cake formation time increased from 15 to 60 seconds. In comparison with the results obtained with the high-porosity filter shown in Figure 7 , the cake moisture produced using the low-porosity filter was lower at all cake formation times except at the cake formation time of 60 seconds. The solids loading shown in Figure 8 also increased from 0.58 to $1.2 \mathrm{~kg} / \mathrm{m}^{2}$ with increasing the cake formation time from 15 to 60 seconds. Comparison of solids loading data for the highporosity filter (Figure 7) and the low-porosity filter (Figure 8) indicates that the low-porosity filter has lower solids loading capacity.

Figure 9 shows the effects of the anionic flocculant dosage on cake moisture and solids loading capacity on the 'as-received' slurry containing 12.8 weight percent solids using the high-porosity filter. The dewatering tests were performed using cake formation time and cake drying time of 30 seconds each. Use of $5 \mathrm{~g} / \mathrm{t}$ flocculant reduced cake moisture from $22.7 \%$ to $15.9 \%$. Higher dosages of flocculant increased cake moisture. The solids loading capacity slightly decreased with the use of the anionic flocculant. Note, that the base line dewatering data in this figure shows filter cake with $22.6 \%$ moisture, compared to one $25.9 \%$ observed in Figure 6 . This variation in filter cake moisture is 


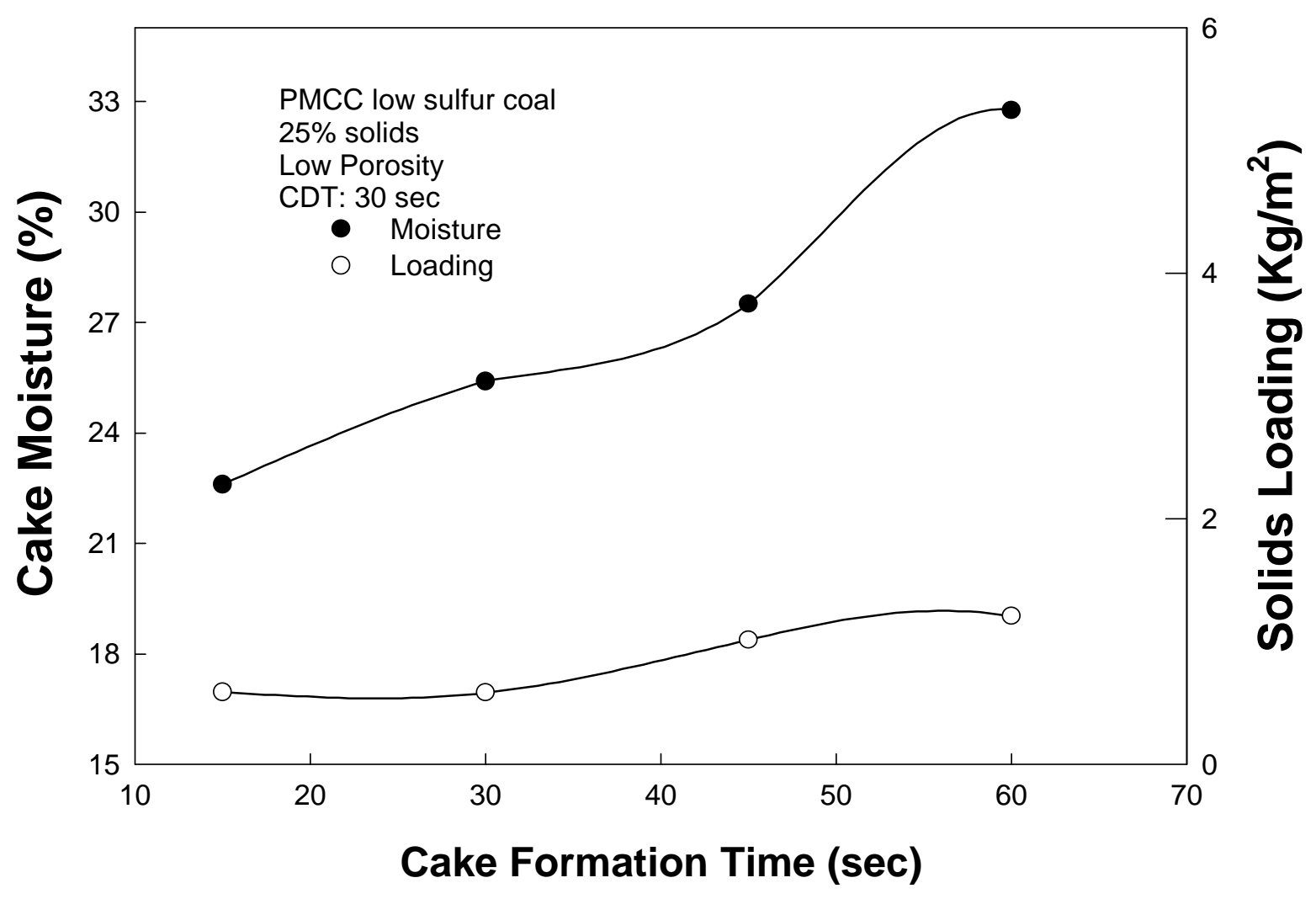

Figure 8. Effects of cake formation time on solids loading and cake moisture using the pre-thickened coal slurry and low porosity filter 


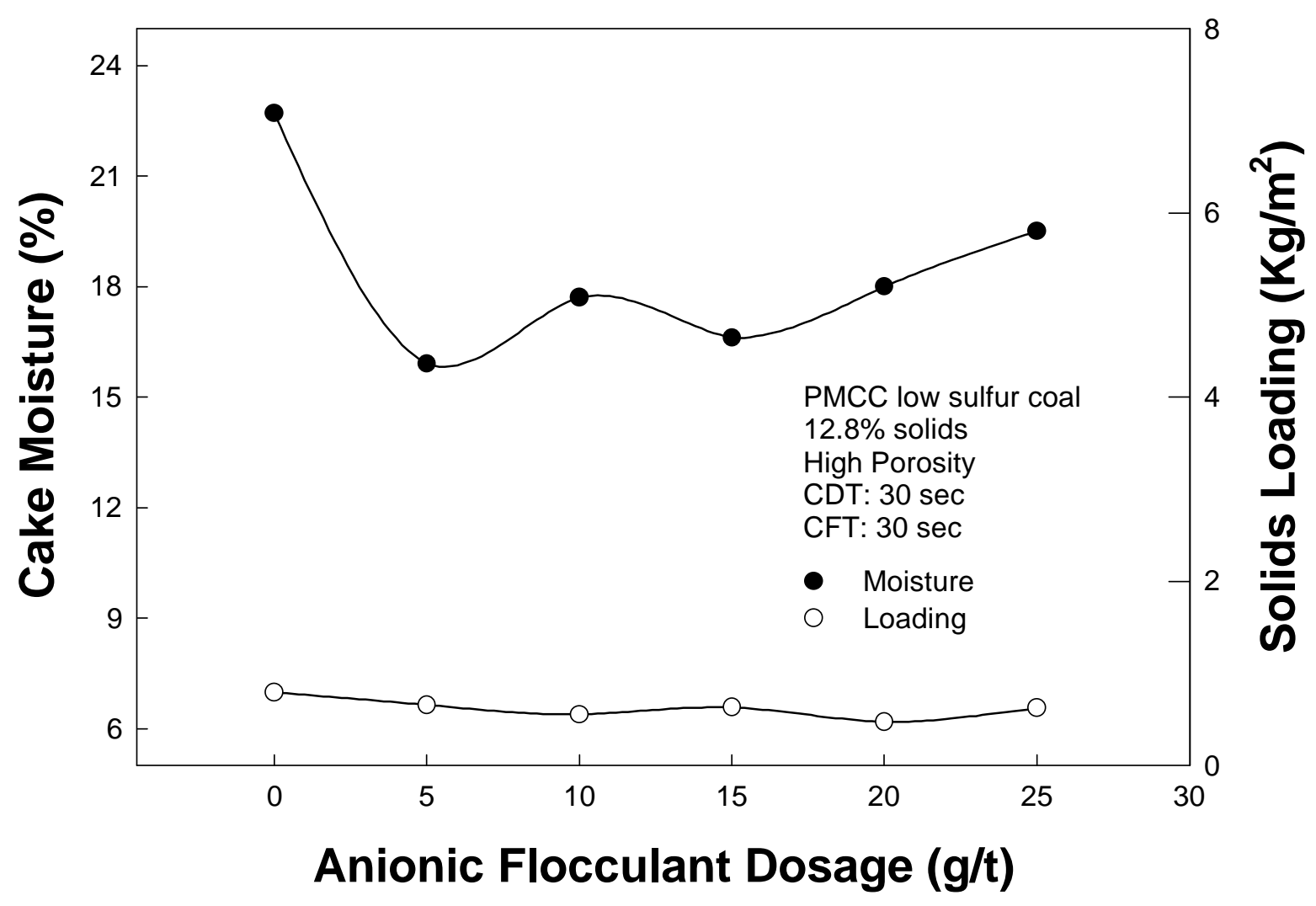

Figure 9. Effects of anionic flocculant on solids loading and cake moisture using the as-received coal slurry and high porosity filter 
attributed to the fluctuating vacuum force observed in the house vacuum during the testing.

Figure 10 shows the effects of anionic flocculant dosage on solids loading and cake moisture using the high-porosity ceramic filter. The dewatering tests were conducted using the 25 weight percent solids concentration, cake formation time of 30 seconds, and cake drying time 30 seconds. As shown in Figure 10 , cake moisture increased from $32.5 \%$ to $36.3 \%$ with increasing the flocculant dosage from 0 to $25 \mathrm{~g} / \mathrm{t}$. The solids loading, on the other hand, increased from 1.86 to $2.42 \mathrm{~kg} / \mathrm{m}^{2}$ as the flocculant dosage increased from 0 to $15 \mathrm{~g} / \mathrm{t}$. However, further increase in the flocculant dosage had adverse impacts on solids loading as well as on cake moisture. Again, in this case, also the baseline dewatering data are different than those observed in Figure 7, which is due to use of house vacuum.

Figure 11 shows the effects of cationic flocculant dosage on cake moisture and solids loading using the high-porosity ceramic filter. The dewatering tests were conducted using 25 weight percent solids concentration, cake formation time of 30 seconds, and cake drying time 30 seconds. The results indicate that use of $10 \mathrm{~g} / \mathrm{t}$ of the cationic flocculant lower the cake moisture from $26.8 \%$ to $25.5 \%$, which is not very significant. However, the solids loading increased considerably with increasing the dosage of the cationic flocculant. At the dosage of $25 \mathrm{~g} / \mathrm{t}$, solids loading increased from the baseline data of $1.56 \mathrm{~kg} / \mathrm{m}^{2}$ to $2.62 \mathrm{~kg} / \mathrm{m}^{2}$, which is significantly higher than that observed 


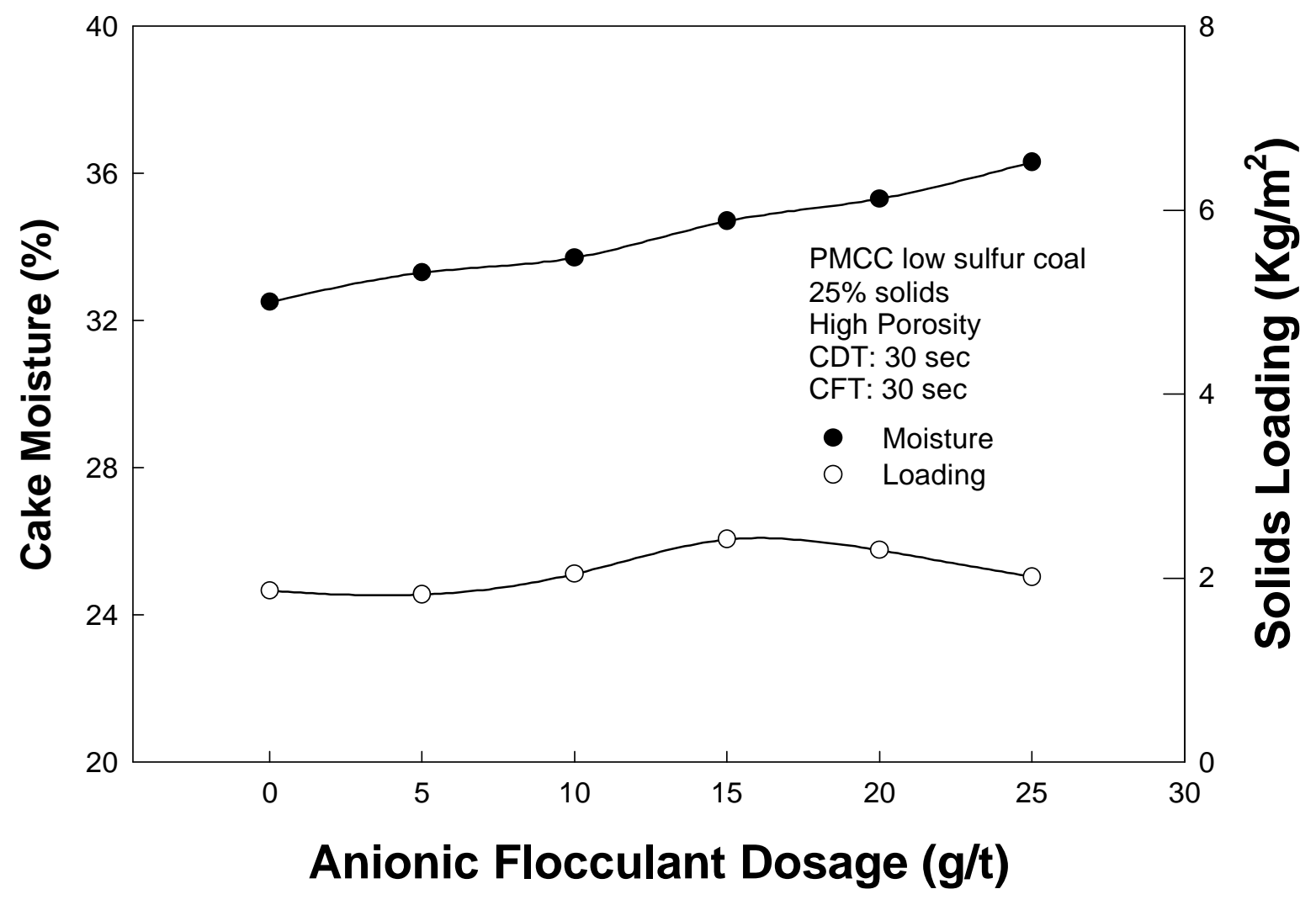

Figure 10. Effects of anionic flocculant dosage on solids loading and cake moisture using the pre-thickened coal slurry and high porosity filter 


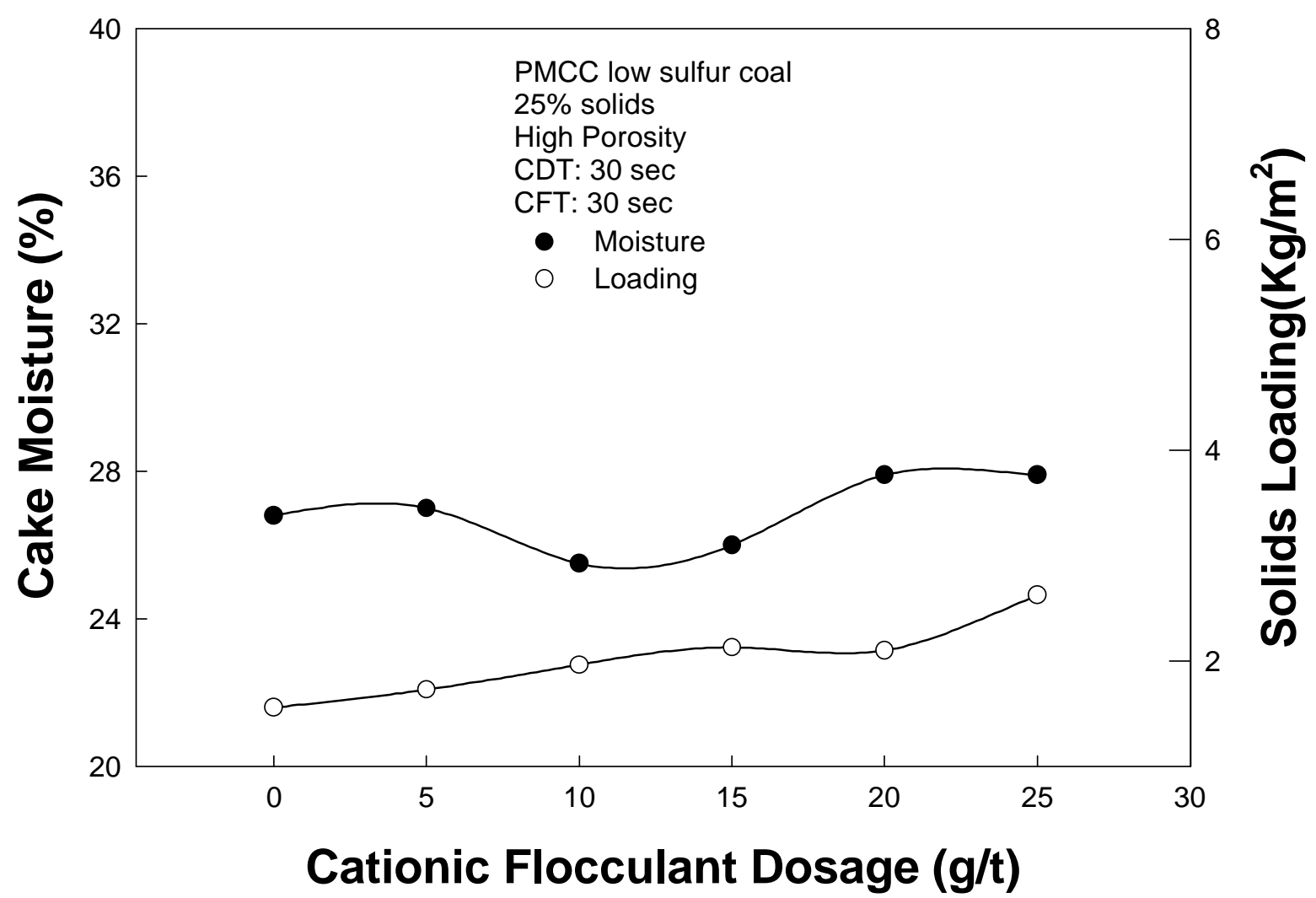

Figure 11. Effects of cationic flocculant on solids loading and cake moisture using the pre-thickened coal slurry and high porosity filter 
with the anionic flocculant.

Figure 12 shows the dewatering test results obtained using the highporosity ceramic filter and 25 weight percent solids slurry as a function of the cationic surfactant CPCL dosage. The filter cake moisture increased from $25.5 \%$ to $29.1 \%$ with increase in surfactant dosage to $0.8 \mathrm{~kg} / \mathrm{t}$. The solids loading obtained in the presence of this surfactant was marginal.

The effect of addition of the cationic surfactant CPCL using the lowporosity ceramic filter is shown in Figure 13. Note, that in this case the solids loading increased from 1.14 to $1.62 \mathrm{~kg} / \mathrm{m}^{2}$ at a surfactant dosage of $1.0 \mathrm{~kg} / \mathrm{t}$. Also, addition of $0.4 \mathrm{~kg} / \mathrm{t}$ of surfactant lowered the cake moisture from $28.1 \%$ to $22.4 \%$, a 5.7 absolute percentage reduction.

It was observed in all these tests that the baseline dewatering data obtained were inconsistent. This was attributed to the fluctuating vacuum force observed during the testing. The higher filter cake moisture obtained with the high-porosity filter could be due to high solids loading (thicker filter cakes) on the filter.

\section{Task 7. Evaluation}

Flowsheet and material balances are being prepared for processing 25 TPH of clean coal using all the four (high pressure, vacuum, centrifuge and ceramic) dewatering techniques investigated in this program. 


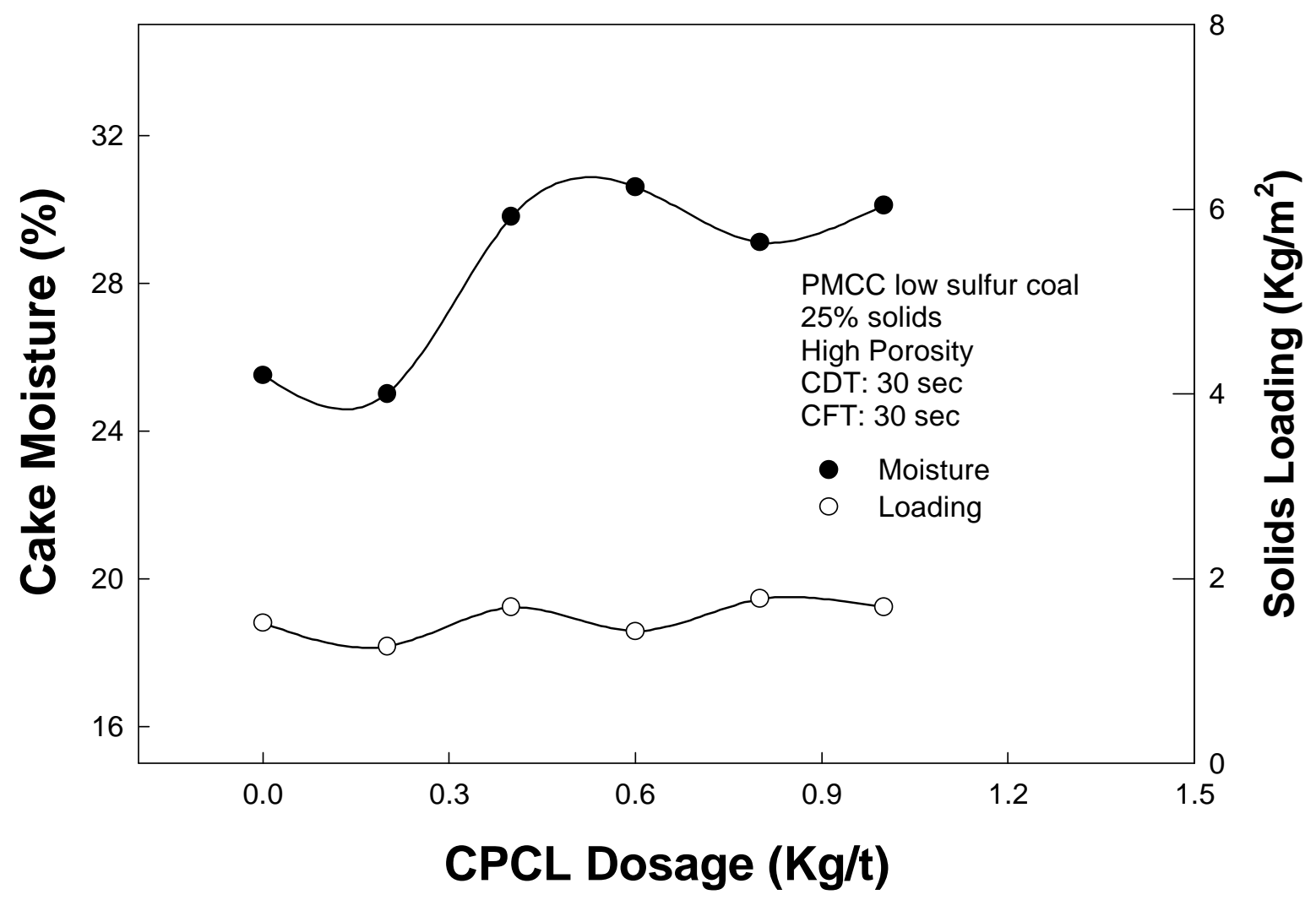

Figure 12. Effects of cationic surfactant on solids loading and cake moisture using the pre-thickened coal slurry and high porosity filter 


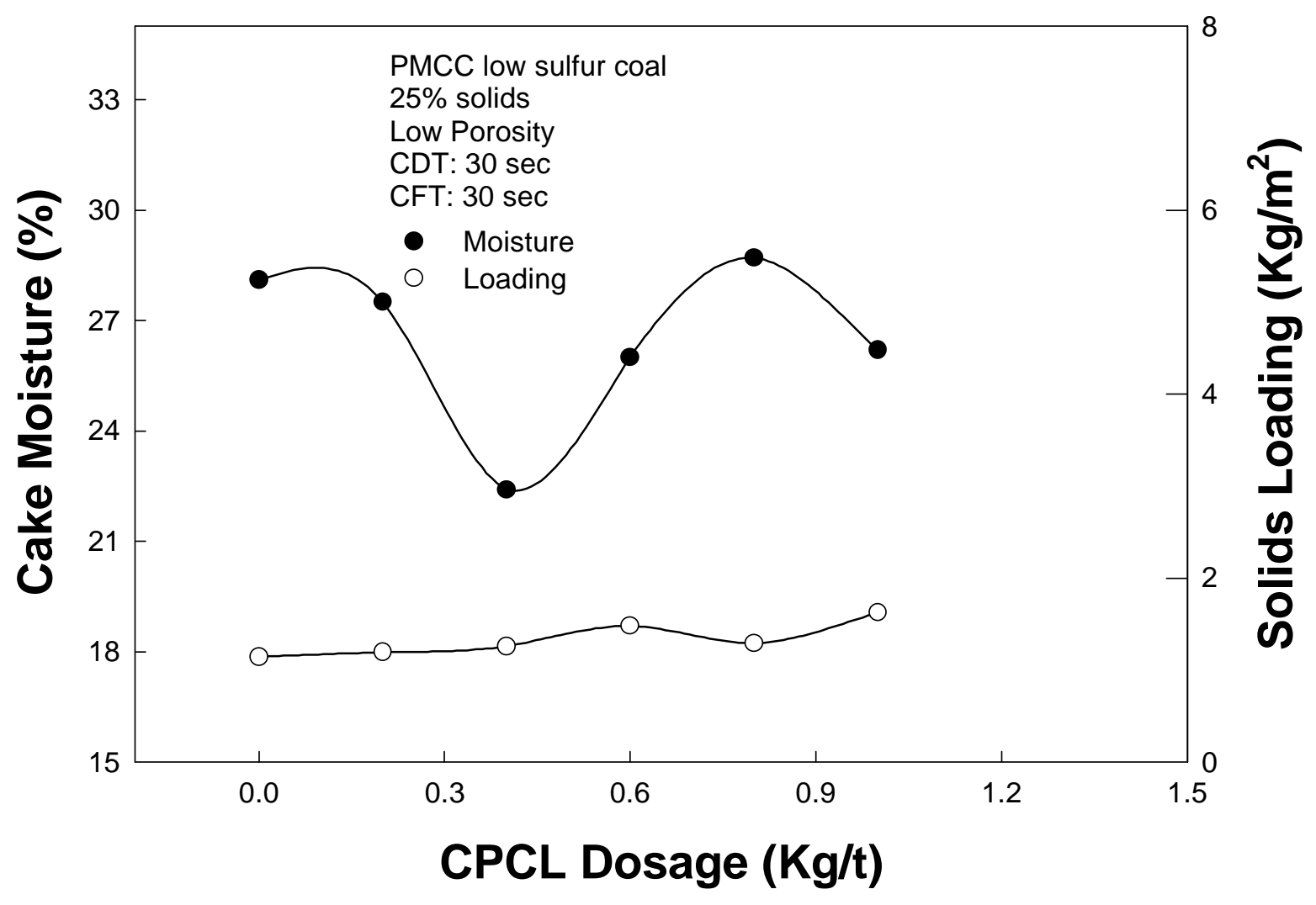

Figure 13. Effects of cationic surfactant on solids loading and cake moisture using the pre-thickened coal slurry and low porosity filter 


\section{CONCLUSIONS}

Based on the laboratory ceramic filtration results shown above, the following conclusions are made:

- Increase in cake formation time increased solids loading more significantly than cake moisture, whereas cake drying time had a great effect on filter cake moisture.

- The effect of cake formation time on solids loading was more significant with low-solids content (12.8 weight percent) slurry than high-solids content (25 weight percent) slurry.

- The low-porosity ceramic filter produced slightly lower solids loading but significantly lower cake moisture than the high-porosity filter. For example, at a 45 second cake formation time and 30 second cake drying time the lowporosity filter produced a cake moisture of $27.5 \%$ and a solids loading 1.00 $\mathrm{kg} / \mathrm{m}^{2}$ while the high-porosity filter generated a cake moisture of $31.2 \%$ and a solids loading of $1.15 \mathrm{~kg} / \mathrm{m}^{2}$. The higher solid loading (thicker filter cake) contributes to higher moisture content.

- Addition of $5 \mathrm{~g} / \mathrm{t}$ of anionic flocculant to the as-received ( $12.8 \%$ solid) slurry reduced cake moisture from $22.7 \%$ to $15.9 \%$ using the high-porosity filter. Using of the anionic flocculant with 25 weigh percent solids slurry, the cake moisture increased from $32.5 \%$ to $36.3 \%$ as the flocculant dosage increased from 0 to $25 \mathrm{~g} / \mathrm{t}$. 
- At 25 weight percent solids addition of $25 \mathrm{~g} / \mathrm{t}$ of the cationic flocculant did not affect the cake moisture, however, solids loading increased from $1.56 \mathrm{~kg} / \mathrm{m}^{2}$ to $2.62 \mathrm{~kg} / \mathrm{m}^{2}$.

- Addition of $0.8 \mathrm{~kg} / \mathrm{t}$ of the cationic surfactant $\mathrm{CPCL}$ to the 25 weight percent solids slurry using high-porosity filter increased filter cake moisture from $25.5 \%$ to $29.1 \%$. However, using the low-porosity filter, addition of $0.4 \mathrm{~kg} / \mathrm{t}$ of the surfactant lowered filter cake moisture from $28.1 \%$ to $22.4 \%$.

- The variation observed in the baseline data could be attributed to the constantly changing house vacuum.

\section{ACTIVITIES FOR NEXT QUARTER}

The dewatering tests using the ceramic leaf filters will be repeated using a portable vacuum pump. The final report preparation will begin. 